\title{
Morphogenesis of aligned collagen fibers in the annulus fibrosus: Mammals versus avians
}

Citation for published version (APA):

Ghazanfari, S., Werner, A., Ghazanfari, S., Weaver, J. C., \& Smit, T. H. (2018). Morphogenesis of aligned collagen fibers in the annulus fibrosus: Mammals versus avians. Biochemical and Biophysical Research Communications, 503(2), 1168-1173. https://doi.org/10.1016/j.bbrc.2018.06.136

Document status and date:

Published: 05/09/2018

DOI:

10.1016/j.bbrc.2018.06.136

Document Version:

Publisher's PDF, also known as Version of record

Document license:

Taverne

Please check the document version of this publication:

- A submitted manuscript is the version of the article upon submission and before peer-review. There can be important differences between the submitted version and the official published version of record.

People interested in the research are advised to contact the author for the final version of the publication, or visit the DOI to the publisher's website.

- The final author version and the galley proof are versions of the publication after peer review.

- The final published version features the final layout of the paper including the volume, issue and page numbers.

Link to publication

\footnotetext{
General rights rights.

- You may freely distribute the URL identifying the publication in the public portal. please follow below link for the End User Agreement:

www.umlib.nl/taverne-license

Take down policy

If you believe that this document breaches copyright please contact us at:

repository@maastrichtuniversity.nl

providing details and we will investigate your claim.
}

Copyright and moral rights for the publications made accessible in the public portal are retained by the authors and/or other copyright owners and it is a condition of accessing publications that users recognise and abide by the legal requirements associated with these

- Users may download and print one copy of any publication from the public portal for the purpose of private study or research.

- You may not further distribute the material or use it for any profit-making activity or commercial gain

If the publication is distributed under the terms of Article $25 \mathrm{fa}$ of the Dutch Copyright Act, indicated by the "Taverne" license above, 


\title{
Morphogenesis of aligned collagen fibers in the annulus fibrosus: Mammals versus avians
}

\author{
Samaneh Ghazanfari a, b, c, *, Arie Werner ${ }^{\mathrm{d}}$, Sara Ghazanfari ${ }^{\text {e, James C. Weaver }}{ }^{\mathrm{f}}$, \\ Theodoor H. Smit a, b, g \\ a Department of Orthopedic Surgery, VU University Medical Center, Amsterdam, the Netherlands \\ ${ }^{\mathrm{b}}$ Amsterdam Movement Sciences, Academic Medical Center and VU University Medical Center, Amsterdam, the Netherlands \\ ${ }^{c}$ Aachen-Maastricht Institue for Biobased Materials, Faculty of Science and Engineering, Maastricht University, Maastricht, the Netherlands \\ d Department of Dental Materials Science, University of Amsterdam and VU University, Amsterdam, the Netherlands \\ e Korteweg-de Vries Institute for Mathematics, University of Amsterdam, Amsterdam, the Netherlands \\ ${ }^{\mathrm{f}}$ Wyss Institute for Biologically Inspired Engineering, Harvard University, Massachusetts, USA \\ ${ }^{g}$ Department of Medical Biology, Academic Medical Center, Amsterdam, the Netherlands
}

\section{A R T I C L E I N F O}

\section{Article history:}

Received 4 June 2018

Accepted 25 June 2018

Available online 4 July 2018

\section{Keywords}

Intervertebral disc

Annulus fibrosus

Collagen arrangement

Notochord

Morphogenesis

\begin{abstract}
A B S T R A C T
The mammalian intervertebral disc (IVD) consists of a gel-like, disordered nucleus pulposus (NP) surrounded by a highly ordered collagen structure, the annulus fibrosus (AF). While this concentric array of lamellae has been amply studied, its physical origin is poorly understood. The notochord is a rod-like organ located in the mid-line of the growing embryo and plays an essential role in IVD development. The aim of this study was to elucidate the effect of notochord development on the collagen fiber arrangement evolution in the AF. To that end, we studied IVD development in mouse embryos and compared these observations to those from chicken embryos, which do not form the typical laminar structure around the NP. In mouse, cross-aligned collagen arrangement of the AF forms from the sclerotome upon bulging of the notochord to become NP. By contrast, the notochord in the chicken embryo swells substantially without the physical restrictions of the future vertebrae and thus do not bulge. From these observations, we conclude that physical and geometrical constrictions are essential for the formation of the highly structured AF.
\end{abstract}

() 2018 Elsevier Inc. All rights reserved.

\section{Introduction}

Lower back pain is often associated with degeneration of the intervertebral disc (IVD). Due to limited success rates of current treatments to restore disc function, tissue-engineering is seen as a promising alternative for IVD replacements [1]. However, in-vitro tissue-engineered IVDs have yet to be used in clinical applications, mainly due to the lack of a well-organized structure needed to provide long-term functionality [2].

While proper functioning of the annulus fibrosus (AF) strongly depends on the fibrous arrangement of collagen fibers [3], the mechanisms that create this collagen anisotropy are not well understood. Different processes, such as cell-induced or strain

\footnotetext{
* Corresponding author. Maastricht University, Urmonderbaan 22, 6167 RD, Geleen, the Netherlands.
}

E-mail address: samaneh.ghazanfari@maastrichtuniversity.nl (S. Ghazanfari). stabilization, have been suggested as underlying mechanisms behind the formation of highly organized collagen fibers [4-7], and building on these previous studies, we propose that mechanical cues and geometrical boundary conditions during embryonic development direct the cross-aligned collagen structure of the AF.

The role of mechanical strain in the development of the skeletal tissues has long been recognized [8,9], and while most attention has been given to the role of mechanics on the alternating bonecartilage pattern formation at the early stages of skeletal development, there have been comparatively fewer studies on the highly organized structure of the AF. In early morphogenesis of vertebrates, the notochord, as an embryonic organ located in the midline of the embryo, develops between the ectoderm and endoderm [10]. After formation of the notochord, an epithelia-like sheath composed of collagen fibrils, laminin, and proteoglycans starts to form around the notochord cells [11,12]. The notochord undergoes one of the two mechanical events during development: 1) Osmotic swelling or vacuolization of the notochord cells resisted by the 
notochord sheath results in an increase in length and width of the notochord, e.g. in chicken and frog [12-14]. 2) After formation of a regular pattern of more condensed cell or future IVD zones and less condensed cell or future vertebra zones, the notochord bulges within the future IVD regions and transforms to the NP in higher vertebrates [15-17]. The notochord, however, persists in all vertebrates except mammals and does not transform to the NP.

Collagen fibers on the notochordal sheath exhibit either a circumferential [11,18] or cross-aligned structure [11,13]. Based on this observation, it is thus likely that the criss-cross aligned collagen structure might exist on the notochord sheath and play a contact guidance role to further guide the alignment of the surrounding collagen matrix in the AF during bulging. Hayes et al. [15-17] showed that after bulging of the notochord, criss-cross alignment of the collagen fibers arises in the AF in rat embryos. However, they did not investigate the structural arrangement of the notochordal sheath or the development of its cross-aligned arrangement.

In the present study, we further investigated the origin of the layered, criss-cross aligned structure of the AF, and whether the alignment is imprinted by the structure of the notochordal sheath, or by the physics of bulging. To address these questions, we studied the embryonic development of collagen fiber alignment in the IVDs in mouse, as a positive model since the notochord transforms to the NP. As a negative model, we used the chick embryo since its notochord does not give rise to the NP. The morphological changes of the notochords were quantified with histological staining and image analysis. The fibrous structure around the notochord was assessed using scanning electron microscopy (SEM) and histology, and immunohistochemistry was performed to reveal collagen orientation changes over time.

\section{Materials and methods}

\subsection{Collection of embryos}

The present investigation conforms to the Guide for the Care and Use of Laboratory Animals published by the US National Institutes of Health (NIH Publication No. 85-23, 1996) and the European Commission Directive 2010/63/EU and was approved by the institutional review board (Academic Medical Center Amsterdam). Three wild type mouse embryos were used for each analysis at the following embryonic days: E10.5, E11.5, E12.5, E13.5, E14.5, E18 (Fig. S1A). At E10.5, the notochord was not yet transformed to the NP and at E18, the IVD was fully developed. Thoracic spines of three sacrificed pregnant females (age $\approx 3$ months) were processed for immunohistochemistry.

Fertilized chicken eggs (Gallus) were obtained from Drost BV (Loosdrecht, NL). The eggs were incubated at $37.5^{\circ}$ and $100 \%$ humidity until the embryos reached the desired stages. Three embryos were used for each analysis at the following HamburgerHamilton (HH) stages [19]: S14, S16, S18, S20, S22, S24 (Fig. S1B). Since the notochord does not transform to the NP in the chicken embryos, comparable stages to those of the mouse embryos were selected (Fig. S1C). Thoracic spines of three adult chickens (age $\approx 3$ months) were processed for immunohistochemistry.

\subsection{Histology}

Embryos were fixed in 4\% paraformaldehyde and processed into paraffin using a standard histological protocol. Transverse serial sections of $10 \mu \mathrm{m}$ were cut from head to tail. Tissue sections were de-paraffinized in xylene and rehydrated in decreasing concentrations of ethanol. For each analysis, every 10th section was analyzed. To quantify the notochord dimensions, the notochord cells were stained with a specific monoclonal antibody (Not-1).
For Not-1 staining, de-waxed paraffin sections were rinsed in phosphate buffered saline (PBS) and subjected to antigen retrieval in $10 \mathrm{mM}$ citrate buffer. To inhibit endogenous peroxidases, samples were incubated with a peroxidase block solution from the Envision kit (Dako, United Kingdom). Thereafter, sections were washed in PBS and non-specific staining was blocked with $2 \%$ BSA. Samples were then incubated with Not-1 primary antibody (1:5, Developmental Studies Hybridoma Bank, USA) for an overnight. Samples were washed with PBS afterwards and incubated with horse anti-mouse IgG biotinylated secondary antibody (1:200, Vector Labs, Inc.) for $1 \mathrm{~h}$ accompanied by incubation with VECTASTAIN ABC Reagent (Vector Labs, Inc.). Samples were incubated with a DAB solution from Envision kit in Tris-buffer for $15 \mathrm{~min}$ to develop peroxidase activity. Finally, all slides were counterstained with Hematoxyline. Immunohistochemistry images were acquired using a Leica EL6000 microscope.

\subsection{Notochord diameter quantification}

Histological images were categorized into 3 groups, showing the notochord as 1) a line (Fig. 1A-1), 2) two circles (Fig. 1A-2) or 3) one circle (Fig. 1A-3). Images from each embryo were serially imported in MATLAB and were registered together (Fig. 2B-I) and corrected for errors (Fig. 2B-II) using standard image processing algorithms. Since the notochord cross-sections were not always circular, the smaller diameter was considered as the notochord diameter. If the larger diameter was 2.5 times longer than the small diameter, the data was excluded from the plot. This case can be seen at E10.5 and E11.5 as the notochord did not yet transform to a rodshaped structure from its flattened form. The diameter as a function of length was obtained, the notochord length was normalized to 1 and a second-order polynomial curve was fitted to the notochord diameter versus normalized length data. To represent one curve per each embryonic stage, the 3 curves obtained from 3 embryos were normalized to the mean curve and $3 \mathrm{R}$-squared values were averaged. The mean diameter was also calculated for each embryonic stage. Mouse embryos at E10.5, E11.5 and E12.5, prior to the notochord transformation to the NP, and chicken embryos at S14, S16, S18, S20, S22 and S24, after the complete vacuolization, were quantitatively analyzed.

\subsection{Scanning electron microscopy (SEM)}

Embryos were fixed in 4\% paraformaldehyde and processed into paraffin using a standard histological protocol. Transverse serial sections of $10 \mu \mathrm{m}$ were cut from head to tail until a desired sectioning plane was reached. Tissue sections were de-paraffinized in xylen serially dehydrated to $100 \%$ ethanol, critically point dried, and imaged with a Tescan Vega GMU scanning electron microscope.

\subsection{Immunohistochemistry}

Fixed embryos at E10.5, E12.5, E14.5 and E18 were embedded in Tissue-Tek OCT compound (Sakura, USA). Adult spines and E18 mouse embryos went through a decalcification process in $4.2 \%$ EDTA (Merck, Germany) solution for 2 weeks prior to embedment in OCT, and were cut through serial $40 \mu \mathrm{m}$ sagittal sections. To investigate the notochord sheath structure in chicken embryos after vacuolization, the dissected notochords from the S18, S20, S22 and S24 embryos were transferred to a petri-dish containing PCsaline to inflate osmotically until reaching the equilibrium state and were fixed afterwards.

To assess the expression of collagen I in mouse samples, the sections were incubated with blocking buffer for $1 \mathrm{~h}$, followed by 

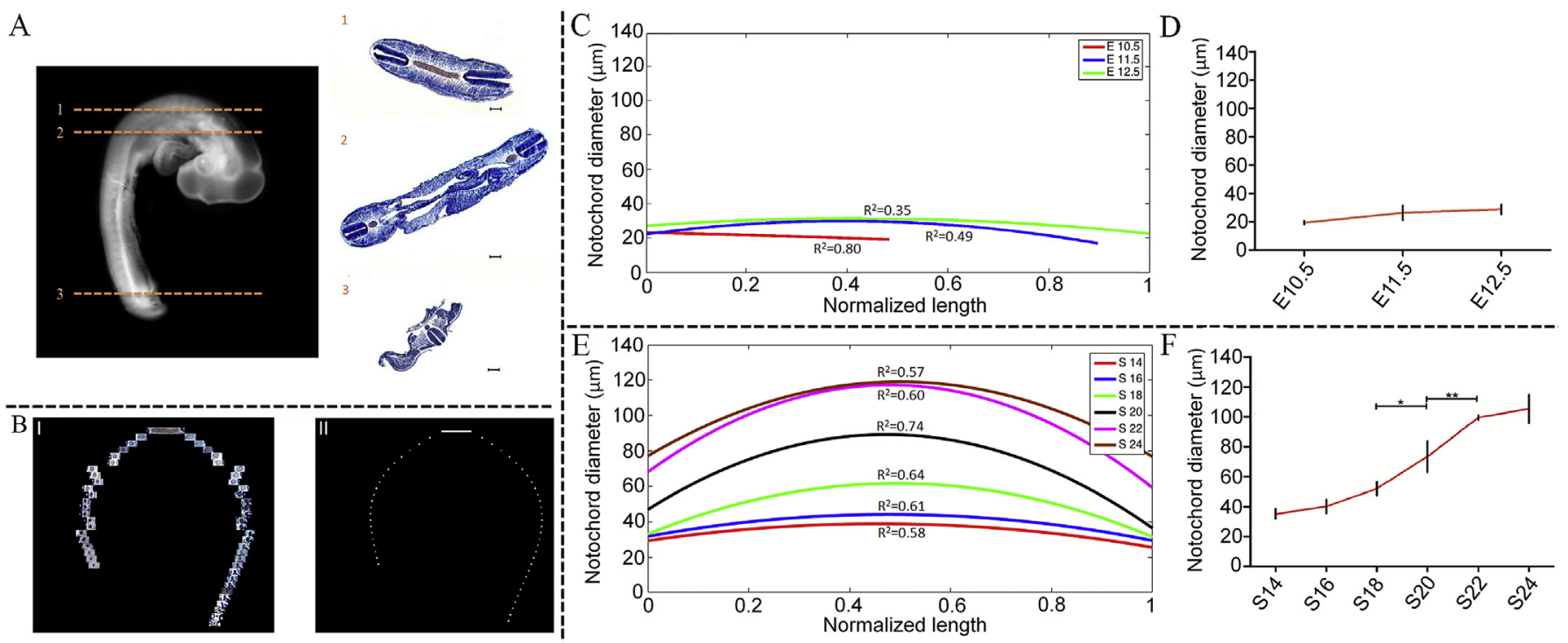

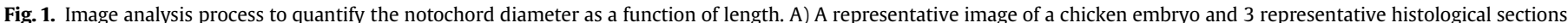

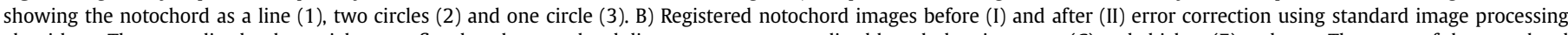

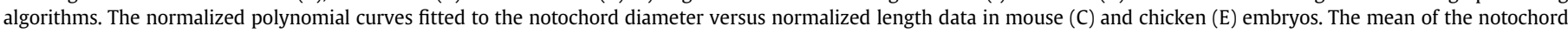
diameter data in mouse (D) and chicken (F) embryos. Scale bar represents $100 \mu \mathrm{m}$.
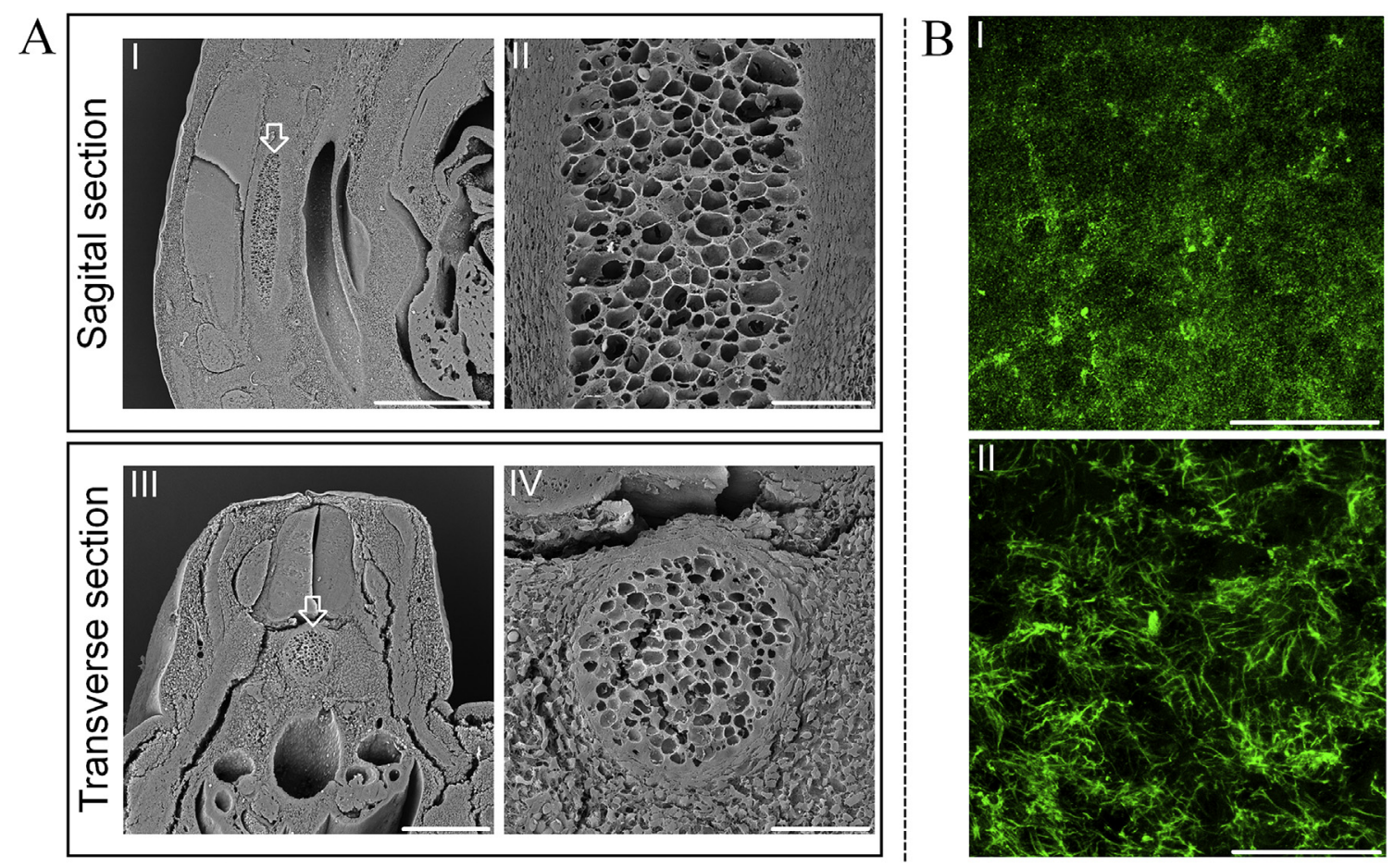

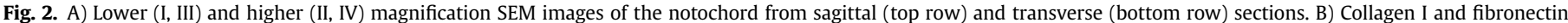
fibers on the notochord sheath. The white arrows indicate the position of the notochord. Scale bar is $500 \mu \mathrm{m}$ (IA), $200 \mu \mathrm{m}$ (IIIA) and $50 \mu \mathrm{m}$ (II, IVA and I, IIB).

$2 \mathrm{~h}$ incubation with rabbit polyclonal anti-collagen I primary antibody (1:1000, Abcam, USA) and $1 \mathrm{~h}$ incubation with Alexa 488 donkey anti-rabbit secondary antibody (1:2000, Invitrogen, USA). After washing, the slides were mounted with Vectashield mounting medium containing DAPI (Vector Laboratories, USA). To probe the expression of collagen I on the chicken adult slides and notochord sheath, samples were incubated with blocking buffer for $45 \mathrm{~min}$ followed by $2 \mathrm{~h}$ incubation with mouse anti-collagen I primary antibody (1:10, Developmental Studies Hybridoma Bank, USA) and
$1 \mathrm{~h}$ incubation with Alexa 488 goat anti-mouse secondary antibody ( $1: 1000$, Invitrogen, USA). To assess the expression of fibronectin on the notochord sheath, samples were incubated with mouse antifibronectin primary antibody (1:10, Developmental Studies Hybridoma Bank, USA) for $2 \mathrm{~h}$, following the application of the blocking buffer, and were then incubated for $1 \mathrm{~h}$ with Alexa 488 goat anti-mouse secondary antibody (1:1000, Invitrogen, USA). Samples were imaged using an inverted confocal microscope (Leica SP8, Germany). 


\subsection{Statistical analysis}

The notochord diameter data were averaged per embryo and then per embryonic stage. To test statistical differences between consecutive developmental stages, student's t-test using GraphPad Prism 6 was performed (GraphPad software, USA). Differences were considered statistically significant at $\mathrm{p}<0.05$.

\section{Results}

\subsection{Notochord diameter quantification}

In mouse embryos (Fig. 1C), at E10.5, the notochord was not yet fully developed into a rod-shaped structure, and the diameter showed a decrease from the anterior part towards the middle. However, at E11.5 and E12.5, the notochord diameter was wider in the middle as compared to the anterior and posterior ends, and the curve appeared more flattened at E12.5 compared to E11.5. Moreover, R-squared of the fitted curves decreased from E10.5 to E12.5 since bulging created an uneven diameter of the notochord throughout the embryos. The notochord mean diameter, slightly, but not significantly, increased in consecutive embryonic stages (Fig. 1D). In chicken embryos (Fig. 1E), the notochord diameter increased much more than in the chick embryo ( $120 \mathrm{vs.} 30 \mu \mathrm{m})$ and was also larger in the middle and decreased towards the anterior and posterior ends. The difference in diameter increased in consecutive stages from S14 to S22. Furthermore, the notochord mean diameter increased from S18 to S20 and S20 to S22 (Fig. 1F).

\subsection{Scanning electron microscopy (SEM)}

In order to investigate the detailed structure of the chick notochord sheath after vacuolization, SEM imaging on S24 was performed. Lower and higher magnification of both sagittal (Fig. 2A-I,II) and transverse (Fig. 2A-III,IV) sections revealed that the highly vacuolated cells were surrounded by a thick and dense tissue layer. Furthermore, there were a few layers of cells (Fig. 2A-IV) that were circumferentially aligned around the notochord.

\subsection{Immunohistochemistry}

Collagen I (Fig. 2B-I) and fibronectin (Fig. 2B-II) staining on the notochord sheath of the chick embryos at S24 showed that collagen I was not structured and the fibronectin was randomly aligned. Laminin and collagen II did not show any alignment either (data not shown) and this did not change for S18, S20 and S22.

In the mouse embryos, collagen fibers on the notochord sheath were aligned circumferentially at E10.5 (Fig. 3A). At E12.5, collagen fibers in both lower (left image) and higher (middle image) magnification images showed a layered structure next to the bulged notochord; however, the cross-aligned structure was not found in the perpendicular plane (right image) (Fig. 3B). Only after complete bulging of the notochord, at E14.5 (left image), the crossaligned collagen fibers were observed (Fig. 3C). Moreover, collagen fiber density increased at stage E18 (Fig. 3C).

A schematic representation (I), top view (II) and sagittal view (III) of an adult mouse (Fig. 4A) and chicken (Fig. 4B) IVD indicated that collagen fibers in the AF had a lamellar (Fig. 4A-II) and crossaligned (Fig. 4A-III) organization in the mouse IVDs. However, in the chicken IVDs, the concentrically aligned (Fig. 4B-II) collagen fibers in the periphery of the disc did not show cross-aligned orientation in the sagittal planes (Fig. 4B-III). Cells elongated and co-aligned with collagen fibers at E14.5 (Fig. 3C, left image) became less elongated at the later stage of E18 (Fig. 3C, right image) and almost rounded in an adult mouse (Fig. 4A-III).

\section{Discussion}

Collagen fiber arrangement in the AF has been shown to be critical for the proper functioning of the IVD. However, it is not yet fully understood how this highly ordered structure forms. This current study aimed to addresses the hypothesis that physical and geometrical constrictions during development create the highly organized collagen arrangement of the AF. Therefore, morphological changes that occur during the IVD development and their consequent effects on the collagen fiber arrangement were investigated.

We evaluated whether the cross-aligned collagen fibers already exist on the notochord sheath and then guide the collagen alignment of the AF. Since the cross-aligned collagen fibers were found neither on the chicken nor mouse notochord, it was concluded that cross-aligned collagen fibers only form after bulging of the notochord into the nucleus pulposus. Grotmol et al. [11] suggested that circumferentially aligned collagen fibers were rearranged to lamellae of criss-cross aligned fibers around the notochord at the later stages of development in Atlantic salmon. It should be noted, however, that this collagen criss-cross alignment in Atlantic salmon appears after hatching when the notochord undergoes straightening concomitant with the length increase, which does not occur in either chicken or mouse [11]. Since the notochord sheath is strained both axially and circumferentially, it is possible that the collagen fibers align along a direction situated between the principal stain directions [20]. Bulging of the notochord applies local biaxial stretch to the future annulus cells and matrices. This mechanical stress could therefore be the underlying mechanism of criss-cross aligned pattern formation of collagen in the AF as the pattern was only observed after this event. The notochord bulging does not occur in avian and thus their AF do not exhibit the crossaligned structure.

It has been suggested previously that hypertrophy of the future vertebra cells, accumulation of proteoglycans, and their osmotic swelling lead to compression of the notochord and a pushing of the notochord cells to the adjacent IVD regions [21]. Moreover, it has been shown that neither disappearance of the notochord cells in the vertebra regions is due to the cell death, nor accumulation of the notochord cells in the IVD regions is due the cell proliferation [22]. Thus, the notochord acts as a passive element in mouse embryos. By contrast, in chicken embryos, the notochord behaves like an active force-exerting element due to osmotic swelling of the notochord cells. The notochord persists as an axial skeleton element throughout life in some species [11], and interestingly, a persistent notochord has also been observed in sacral agenesis patients having abnormal ossification of the vertebral bodies. The patient had mutations in the T-box (brachyury) gene, which causes delay in mesoderm differentiation and ossification process [23]. This clinical study demonstrated that the notochord persisted when the ossification of the cartilage cells was delayed, meaning that a periodic external force from the swelling precursor vertebrae is essential for the transformation of the notochord to the NP.

Image analysis of the serial sections throughout the whole embryos described here also showed that the notochord diameter varied both spatially and temporally. Within one embryo, the diameter was wider in the middle as compared to the ends; this spatial morphological characteristic is also seen in the "tapered notochord" of ascidians [24]. The mechanism of tapering in the ascidian notochord is related to the unequal developmental timing of intercalation from the anterior-posterior ends towards the middle, the rates of notochord cell narrowing transition, and cell volume partitioning [24]. Additionally, the notochord mean diameter significantly increased from S18 to S20 and S20 to S22 in chicken embryos when the vacuolization was pronounced (Figs. S2 

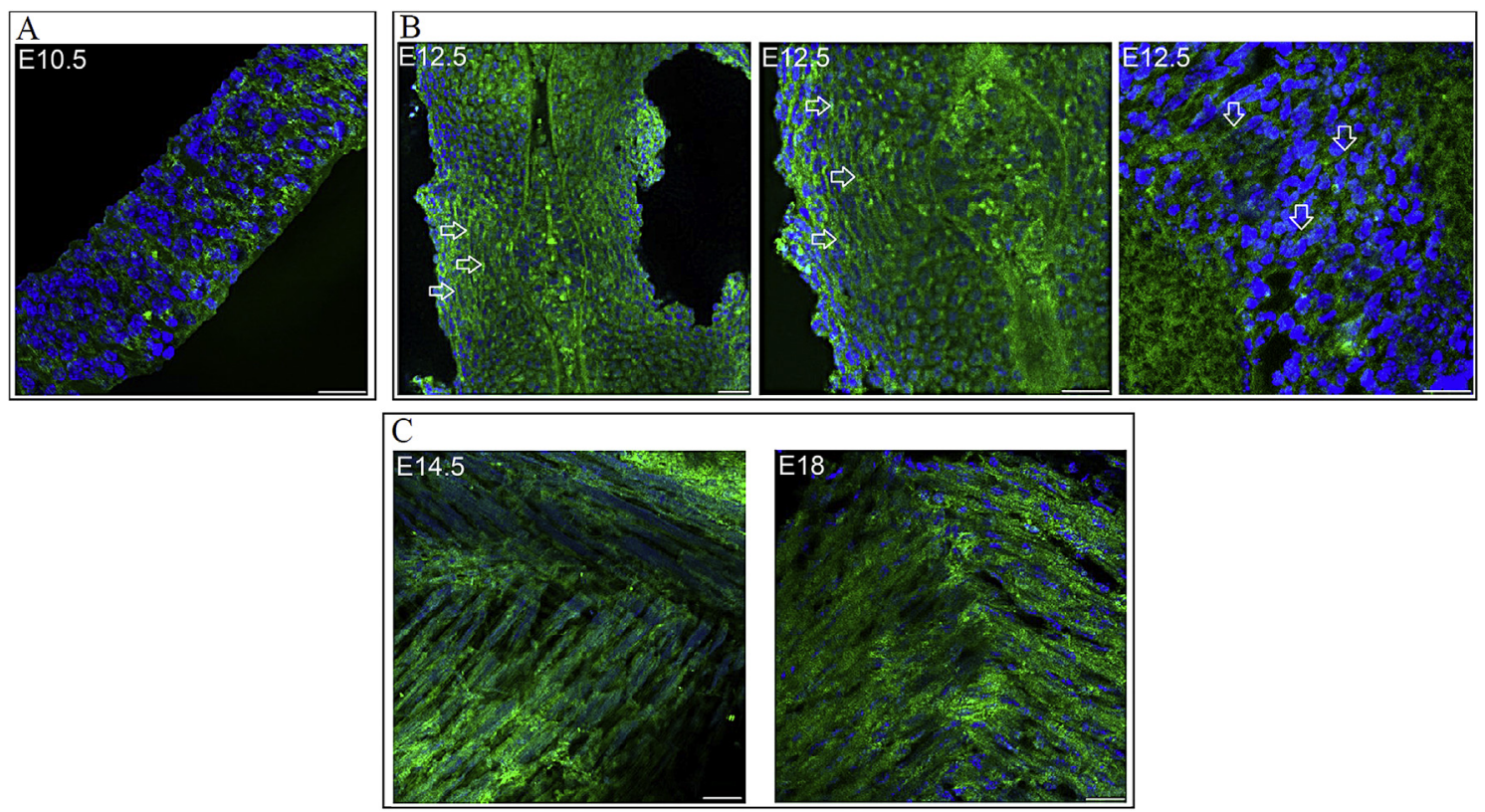

Fig. 3. A) Collagen fibers (green) and cell nuclei (blue) on the notochord sheath at E10.5. B) Collagen fiber structure in the vicinity of the dilated notochord in both lower (left) and higher (right) magnification images at E12.5. C) The cross-aligned collagen fibers at E14.5 (left) and E18 (right). The white arrows point at the collagen layers. Scale bar represents $25 \mu \mathrm{m}$. (For interpretation of the references to colour in this figure legend, the reader is referred to the Web version of this article.)
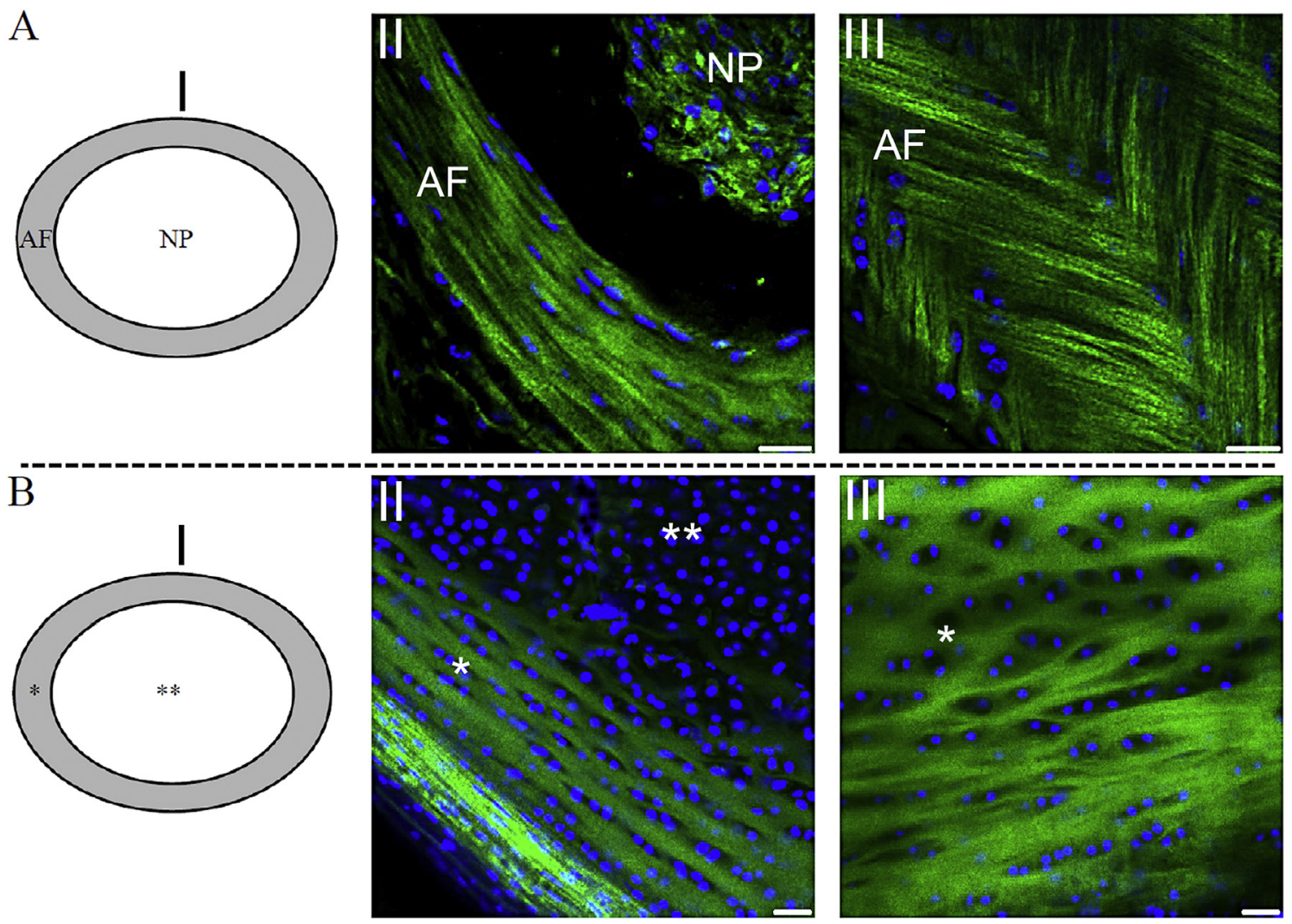

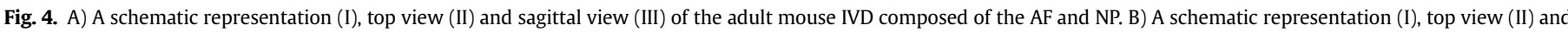
sagittal view (III) of the adult chicken IVD composed of the AF-like $\left(^{*}\right)$ and NP-like $\left.{ }^{* *}\right)$ regions.

and S3). Notochord vacuolization and therefore, significant increase in the notochord diameter were, however, not seen in the mouse embryos. Thus, it seems that vacuolization of notochord cells only happens upon bulging in mammals like mice.
In conclusion, this study provides in-vivo information on the development of the collagen fiber arrangement from early stages on the notochord sheath towards a highly organized structure of the AF in mammals. We suggest that mechanical forces in and 
around the notochord, rather than alinment of the notochordal sheath, define the architecture of the IVDs. In mammals, the bulging notochord applies a bi-axial strain in the sclerotome between the condensations, which then induces the criss-cross aligned structure of cells and matrix. However, the IVDs in birds do not show such a structure as the avian notochord is not squeezed. To recapitulate the native-like microenvironment to tissue-engineer lamellar, criss-cross structure in-vitro, the proposed mechanisms behind the formation of highly organized fibers can be applied. By designing an in-vitro model system considering the in-vivo parameters, we can better evaluate and optimize the factors that affect this pattern formation, which may ultimately lead to the development of novel strategies for the regeneration of well-structured functional IVDs.

\section{Acknowledgments}

Samaneh Ghazanfari and Theodoor H. Smit acknowledge financial support from a ZonMW-VICI grant 918.11.635. The authors thank Vincent Christoffels and Corrie de Gier-de Vries for kindly providing the mouse embryos.

\section{Appendix A. Supplementary data}

Supplementary data related to this article can be found at https://doi.org/10.1016/j.bbrc.2018.06.136.

\section{References}

[1] S.M. Richardson, A. Mobasheri, A.J. Freemont, et al., Intervertebral disc biology, degeneration and novel tissue engineering and regenerative medicine therapies, Histol. Histopathol. 22 (2007) 1033-1041.

[2] N.L. Nerurkar, D.M. Elliott, R.L. Mauck, Mechanical design criteria for intervertebral disc tissue engineering, J. Biomech. 43 (2010) 1017-1030.

[3] P. Fratzl, in: Collagen: Structure and Mechanics, Springer Science \& Business Media, Berlin, 2008

[4] S. Ghazanfari, A. Driessen-Mol, B. Sanders, et al., Evolution of in-vivo collagen remodeling and maturation in the vascular wall of decellularized stented tissue engineered heart valves, Tissue Eng. 21 (2015) 2206-2215.

[5] S. Ghazanfari, A. Driessen-Mol, S.P. Hoerstrup, et al., Collagen matrix remodeling in stented pulmonary arteries after trans-apical heart valve replacement, Cells Tissues Organs 201 (2016) 159-169.
[6] S. Ghazanfari, A. Driessen-Mol, C.V.C. Bouten, et al., Modulation of collagen fiber orientation by strain-controlled enzymatic degradation, Acta Biomater. 35 (2016) 118-126.

[7] S. Ghazanfari, A. Khademhosseini, T.H. Smit, Mechanisms of lamellar collagen formation in connective tissues, Biomaterials 97 (2016) 74-84.

[8] D.D. Klumpers, D.J. Mooney, T.H. Smit, From skeletal development to tissue engineering: lessons from the micromass assay, Tissue Eng. B Rev. 21 (2015) 427-437.

[9] L. Truskinovsky, G. Vitale, T.H. Smit, Mechanical perspective on vertebral segmentation, Int. J. Eng. Sci. 83 (2014) 124-137.

[10] A. Fleming, R. Keynes, D. Tannahill, A central role for the notochord in vertebral patterning, Development 131 (2004) 873-880.

[11] S. Grotmol, H. Kryvi, R. Keynes, et al., Stepwise enforcement of the notochord and its intersection with the myoseptum: an evolutionary path leading to development of the vertebra? J. Anat. 209 (2006) 339-357.

[12] M.J. Parsons, S.M. Pollard, L. Saude, et al., Zebrafish mutants identify an essential role for laminins in notochord formation, Development 129 (2002) 3137-3146.

[13] D.S. Adams, R. Keller, M.A. Koehl, The mechanics of notochord elongation, straightening and stiffening in the embryo of Xenopus laevis, Development 110 (1990) 115-130.

[14] K. Ellis, J. Bagwell, M. Bagnat, The vacuole within how cellular organization dictates notochord function, J. Cell Biol. 3 (2013) 64-68.

[15] A.J. Hayes, M. Benjamin, J.R. Ralphs, Roles of actin stress fibres in the development of the intervertebral disc: cytoskeletal control of extracellular matrix assembly, Dev. Dynam. 215 (1999) 179-189.

[16] A.J. Hayes, M. Benjamin, J.R. Ralphs, Extracellular matrix in development of the intervertebral disc, Matrix Biol. 20 (2001) 107-121.

[17] A.J. Hayes, M.D. Isaacs, C. Hughes, et al., Collagen fibrillogenesis in the development of the annulus fibrosus of the intervertebral disc, Eur. Cell. Mater. 22 (2011) 226-241.

[18] D. Corallo, V. Trapani, P. Bonaldo, The notochord: structure and functions, Cell. Mol. Life Sci. 72 (2015) 2989-3008.

[19] V. Hamburger, H.L. Hamilton, A series of normal stages in the development of the chick embryo, J. Morphol. 88 (1951) 49-92.

[20] N.J.B. Driessen, W. Wilson, C.V.C. Bouten, et al., A computational model for collagen fibre remodelling in the arterial wall, J. theoretical boil 226 (2004) 53-64.

[21] V. Sivakamasundari, T. Lufkin, Bridging the gap: understanding embryonic intervertebral disc development, Cell Dev. Biol. 1 (2012) 103.

[22] A. Aszodi, D. Chan, E. Hunziker, et al., Collagen II is essential for the removal of the notochord and the formation of intervertebral discs, J. Cell Biol. 143 (1998) 1399-1412.

[23] A.V. Postma, M. Alders, M. Sylva, et al., Mutations in the T (brachyury) gene cause a novel syndrome consisting of sacral agenesis, abnormal ossification of the vertebral bodies and a persistent notochordal canal, J. Med. Genet. 51 (2014) 90-97.

[24] M.T. Veema, W.C. Smith, Whole-organ cell shape analysis reveals the developmental basis of ascidian notochord taper, Dev. Biol. 373 (2013) 281-289. 